\title{
Development and Validation of the Social and Emotional Competencies Evaluation Questionnaire
}

\author{
Vitor Alexandre Coelho ${ }^{1}$, Vanda Sousa ${ }^{1} \&$ Marta Marchante $^{1}$ \\ ${ }^{1}$ Académico de Torres Vedras, Torres Vedras, Portugal \\ Correspondence: Vitor Alexandre Coelho, Rua Manuel Agro-Ferreira, 72, R/C 2825-362, Costa da Caparica, \\ Portugal. E-mail: vitorpcoelho@gmail.com
}

Received: February 27, 2015

Accepted: April 2, 2015

Online Published: April 24, 2015

doi:10.5539/jedp.v5n1p139

URL: http://dx.doi.org/10.5539/jedp.v5n1p139

\begin{abstract}
This study presents the construction and validation of an instrument for assessing social and emotional competencies in adolescents. The Social and Emotional Competences Evaluation Questionnaire (QACSE) is based on three previous instruments and constructed according to the theoretical framework proposed by the Collaborative for Academic, Social and Emotional Learning (2005).

The questionnaire was validated in a sample of 683 high middle school students (7th to 9th grade), with an average age of 12.91 years. Six teachers also participated by filling the teacher version regarding 111 students on the sample. Results showed that the QACSE presents good levels of reliability and validity; including a sound five dimension factor structure.

The final version of the $Q A C S E$ is composed by 39 items, organized into five scales that assess the following social and emotional competencies: self-control, social awareness, relationship skills, social isolation and social anxiety. The QACSE takes around 10 minutes to fill and is appropriate for individual or group use for the evaluation of the aforementioned competencies. This questionnaire assesses most of the key competencies identified by the Collaborative for Academic Social and Emotional Learning (2012).
\end{abstract}

Keywords: Social and Emotional Learning (SEL), self-reports, program evaluation

\section{Introduction}

The number of Social Emotional Learning (SEL) programs has increased exponentially (Durlak, Weissberg, Dymnicki, Taylor, \& Schellinger, 2011), however, this growth has not been accompanied by the development of appropriate instruments for the evaluation of social and emotional competences or SEL programs (Sandell et al., 2012). This is a persisting problem in the literature, since Merrell (2001) had already warned that there was little evidence of the adequateness of existent instruments in the field, naming only one as being adequately developed for the specific evaluation of social skills: the Social Skills Rating System (SSRS; Gresham \& Elliott, 1990).

Presently, Social and Emotional Learning (SEL) is defined by the Collaborative for Academic, Social, and Emotional Learning (CASEL, 2012) as "the processes through which children and adults acquire and effectively apply the knowledge, attitudes, and skills necessary to understand and manage emotions, set and achieve positive goals, feel and show empathy for others, establish and maintain positive relationships, and make responsible decisions". These social and emotional competencies are fundamental for success in school and in life (Zins, Weissberg, Wang, \& Walberg, 2004) and additionally they also have a preventive effect against bullying, peer pressure, inappropriate behaviour toward adults and risk behaviours (Durlak et al., 2011; Sklad et al., 2012).

CASEL (2012) recommended that SEL programs should have as goals the development of five key interrelated sets of social, emotional and cognitive competencies, namely:

Self-awareness: to be aware of one's internal states; knowing how to identify and recognize emotions, to be able to perform a realist evaluation of one's capacities, needs and values; and to establish a sense of self-concept, self-efficacy and self-esteem;

Social awareness: to respect and understand what others are feeling, being able to adopt another's perspective, show respect and consideration for others; to be able to interact in positive way with diverse groups; 
Self-Control: to control impulses, manage stress and emotions, self-motivation and discipline, to establish goals and to able to postpone rewards in order to reach them, persistence and resistance to frustration and adversity;

Relationship skills: dealing effectively with emotions in relationships, to adequately use verbal and non-verbal communication, work cooperatively, to generate and maintain healthy and rewarding relationships, to resist negative peer pressure, adequately manage conflicts, negotiate solutions and seek help, when help is needed;

Responsible decision taking: taking decision based on an analysis of all relevant factors and likely consequences of different courses of action as well as taking personal responsibility for one's decisions.

CASEL (2012) also warns about the importance of establishing continuous evaluation of implementation procedures (allowing for a revision and improvement of pedagogical contents and practices), as well as of its results (focused on the analysis of effectiveness and also of the impact on children's lives), using quality methodologies and instruments, (Greenberg et al., 2003; CASEL, 2005).

\subsection{Social and Emotional Competencies Evaluation Questionnaire}

This study is part of a set of similar studies that seek to establish a multi-informant (students, teachers and parents) set of evaluation questionnaires to be used in the evaluation of SEL programs efficacy and effectiveness, adequate for the use with middle school students (12 to 16 years), and based on the CASEL theoretical framework (Greenberg et al., 2003; CASEL, 2005). This need arose from the work developed in Project "Positive Attitude", a project dedicated to promoting healthy behaviours and reducing risk behaviour through the promotion of social and emotional competencies in the school setting. It is based on the methodologies proposed by CASEL (2005). During the first four years of the project, late middle school students often complained about the previously used evaluation instrument (Bateria de Socialização 3; Silva \& Martorell, 1995; Portuguese adaptation by Ferreira \& Rocha, 2004), due to its length and its overly simplified answer format. So there was a need to develop a more appropriate questionnaire to assess the effectiveness of Portuguese SEL programs.

The present instrument is based on three previous instruments: Bateria de Socialización 1 (BAS-1; Silva \& Martorell, 2001), Social Skills Rating Scale (SSRS; Gresham \& Elliott, 1990) and the School Social Behavior Rating Scale (SSBS; Merrell, 2002); amply used in Portugal and Spain, but that do not correspond to the adopted theoretical framework, and, as such, are not adequate for assessment of the Project.

\subsection{Previous Instruments}

The Bateria de Socialización 1 (Silva \& Martorell, 2001) is an instrument answered by teachers (118 items) focusing on children and adolescents (ages 6 to 15) behaviour in the school setting. The answer format is a 4-point scale (A meaning "Never", B-“Sometimes", C-“Frequently" and D-“Always"). The instrument is composed by 8 scales, including a Global Socialization Scale (15 items), four scales measuring facilitating aspects of socialization: Leadership (17 items; evaluates popularity, initiative, self-confidence); Extraversion (12 items; measuring extroversion and good mood); Social Sensitivity (14 items; evaluating the degree of consideration and respect towards other people) and Respect/Self-control (18 items; appreciates following social rules and norms, responsibility and self-criticism); as well as three scales that evaluate inhibitors of socialization: Aggressiveness (17 items; identifies elements of impulsive or anti-social behaviour, resistance to rules as well as verbal or physical aggressiveness); Apathy (19 items; evaluates social isolation, introversion, aloofness, apathy and, in extreme degrees depression) and Anxiety/Shyness (12 items; measures anxiety, fear, shyness and shame). No significant differences were found due to place of residence (rural/urban) or school type (public or private). Regarding gender, teachers rate girls as having higher levels of general socialization skills, respect/self-control and anxiety/shyness, while attributing higher level of apathy to boys (Silva \& Martorell, 2001).

The Social Skills Rating Scale (SSRS; Gresham \& Elliott, 1990; Portuguese adaptation by Lemos \& Meneses, 2002) is also a teacher form, assessing students from the 3th to the 6th grades, and directed at the simultaneous evaluation of social and academic competency. The SSRS is composed by three dimensions: Social Skills (composed by Cooperation, 9 items; Self-Control, 10 items and Assertion, 10 items); Behaviour Problems, composed by three factors: Externalized Problems (6 items; evaluating verbal and physical aggression), Internalized Problems (6 items; focused on the anxiety, sadness and isolation) and Hyperactivity (6 items; regarding impulsive behaviours and general agitation); as well as Academic Competence (6 items) focusing on school performance, namely Portuguese and mathematics. In this version, all items are answered in a three-point Likert-type scale (1-“never"; 2-“"sometimes"; 3-“many times").

The School Social Behavior Rating Scale (SSBS-2; Merrell, 2002), partially adapted to the Portuguese population by Raimundo and colleagues (2012), is also an instrument for teacher report, developed for the 
assessment of social skills and antisocial behaviour of children from kindergarten to the 12th grade. The original instrument was comprised of two scales, however the Portuguese adaptation only included the social skills scales, 32 items evaluated in a 5-point Likert-type scale (from 1 meaning "never" to 5-"very frequent"), which describe positive or adaptive behaviours that should lead to personal and socially positive outcomes. It is composed by three subscales: Relations with peers, Self-Control and Academic Behaviour (Merrell, 2002). In the Portuguese adaptation, girls presented higher levels of Self-Control and Academic Behaviour (Raimundo et al., 2012).

\section{Method}

\subsection{Participants}

The Social and Emotional Competences Evaluation Questionnaire (QACSE) was applied to a sample of 683 middle school students (7th to 9th grade): 440 students from the 7th grade, 204 students from the 8th grade and 39 students from the 9 th grade, evenly distributed between genders ( $N=367,53.8 \%$ boys). The average age was $12.91(S D=1.23)$. All students frequented six public school groupings schools in the Lisbon District, during two school years (2008/09 and 2009/10). 168 students frequented schools in an urban setting and 415 frequented schools in a rural schools. Six teachers also participated (three 7th grade class directors and three 8th grade class directors). These teachers filled the teacher report form of the questionnaire ( $Q A C S E-P$; Coelho, Sousa, \& Figueira, 2014) about 111 students who were part of the samples.

\subsection{Measures}

Along with the $Q A C S E$, two other instruments were applied in order to perform the analysis pertaining to validity: these were the Bateria de Socialização 3 (BAS-3; Ferreira \& Rocha, 2004) and the Social and Emotional Competencies Evaluation Questionnaire - teachers form (QACSE-P; Coelho, Sousa, \& Figueira, 2014).

\subsubsection{Social and Emotional Competencies Evaluation Questionnaire-Development of Items and Scales}

The Social and Emotional Competences Evaluation Questionnaire ( $Q A C S E$ ) was developed to evaluate the social and emotional competencies of children and adolescents (12 to 16 years) is meant to be a shorter self-report instrument, with a more elaborate answer format and with a better correspondence to the questionnaires for other informants developed by the project.

In order to achieve this, the items from three questionnaires (BAS-1, SSRS and SSBS-2) were assembled and analysed by three psychologists, following the theoretical framework adopted (CASEL, 2005). The items were paired and eliminated, if found redundant. The set of 76 items that resulted from the previous procedure was analysed by four teachers, who suggested the removal of six items due to their extreme likeness. These procedures led to the creation of an initial version of the questionnaire, composed by 70 items, and that included a Sincerity scale (six items; e.g. "I share all my things with others").

The answer format adopted corresponded to the need of establishing a correspondence with the teachers' version of instrument. As such, students answered in a four-point Likert-type scale: A meaning "Never", B-"Sometimes", C- "Frequently" and D-“Always" (with "never" corresponding to "0", "as" to "1", "frequently" to " 2 " and "always" to " 3 "). The scale results are given by summing individual items. There were 14 items formulated negatively and therefore reversely scored (eg., "I protest when I am told to do something"; in this items A would be score as " 3 " and so on).

\subsubsection{Bateria de Socialização 3}

The Bateria de Socialização 3 (BAS-3; Silva \& Martorell, 1995; Portuguese adaptation by Ferreira \& Rocha, 2004) is a self-report instrument that allows for the assessment of students' perception (ages comprised between 11 and 18 years) regarding their social behaviour. The 75 items are answered in a Yes or No format and the questionnaire is comprised of five scales: Consideration for Others (14 items; assessing the degree of sensibility and concern for others), Self-control in Social Relations (14 items; evaluates the acceptance of social rules and, on the other hand aggressive or overbearing behaviours), Social isolation (14 items; allows to detect an active or passive detachment from the group), Social anxiety/Shyness (12 items; evaluates anxiety and shyness in social situations) and Leadership (12 items; focusing on popularity, initiative, self-confidence and availability towards others). The BAS-3 also integrates a 10-item sincerity scale.

\subsubsection{Social and Emotional Competencies Evaluation Questionnaire-Teachers Version}

The Social and Emotional Competencies Evaluation Questionnaire-Teachers version (QACSE-P; Coelho, Sousa, \& Figueira, 2014) assesses teachers perception regarding the social behaviour of their students, and is 
composed by 56 items distributed along 5 scales: Social awareness (10 items; e.g. "He/she worries when someone has a problem"), Self-control (12 items; e.g. "When he/she wants to speak, he asks and waits for his/her turn"), Relationship skills (13 items; e.g. "He/she is capable of discussing rules that he/she believes are unfair"), Social isolation (12 items; e.g. "He/she isolates himself/herself and doesn't talk to anyone") and Social anxiety (9 items; e.g."When faced with new situations he/she is afraid"). The answer format is identical to the QACSE.

\subsection{Procedure}

The questionnaire was applied to students who were part of a triage for potential inclusion in the SEL program "Positive Attitude". Evaluation took place after obtaining authorization from school boards and parents, following national legislation. The instrument was applied in classes by the project's psychologist in the presence of the teachers. Questionnaires instructions were read out aloud. Students who also took part in the time-retest evaluation of the instrument, filled the QACSE again three months after the first assessment, these students were part of the control groups for this program. These students also filled up the BAS-3, during school year 2008/09, in order to analyse concurrent validity. The teacher questionnaire $(Q A C S E-P)$ was delivered by the project's psychologist for that school grouping to the class director who, later, returned them duly filled. Questionnaires that were returned more than two weeks after their delivery were removed.

\section{Results}

\subsection{Preliminary Factor Analysis}

The results of the preliminary factor analysis showed that 29 items (out of 70) did not present loadings higher than .40 in any factor and were removed, following the suggestions by Floyd and Widaman (1995). According to same authors, a loading higher than .30 in a second factor is also a reason for excluding that item. The resulting 41 items where then subjected to several procedures of factorial analysis, using different rotation technics and several solutions were analysed. The solution which resulted in an easier interpretation was a Principal Components Analysis, with a Varimax rotation (with Kaiser normalization) forced to five factors that explained $42.16 \%$ of the variance.

Table 1. Exploratory factorial analysis, principal components method, with varimax rotation, for the $Q A C S E$

\begin{tabular}{|c|c|c|c|c|c|c|c|c|c|}
\hline \multirow{2}{*}{$\begin{array}{l}\text { Social Awareness } \\
\text { 25. I help other with } \\
\text { their problems }\end{array}$} & & \multicolumn{2}{|l|}{ Social Isolation } & \multicolumn{2}{|l|}{ Self-control } & \multicolumn{2}{|l|}{ Social Anxiety } & \multicolumn{2}{|c|}{ Relationship Skills } \\
\hline & .748 & $\begin{array}{l}28 . \quad \text { I isolate } \\
\text { myself }\end{array}$ & .743 & $\begin{array}{l}\text { 32. I wait for } \\
\text { my turn }\end{array}$ & .680 & $\begin{array}{l}\text { 36. I feel often } \\
\text { ashamed }\end{array}$ & .762 & $\begin{array}{l}\text { 12. I organize } \\
\text { groups }\end{array}$ & .624 \\
\hline $\begin{array}{l}\text { 13. I worry when } \\
\text { others have problems }\end{array}$ & .745 & $\begin{array}{l}\text { 42. I withdraw } \\
\text { and don't speak }\end{array}$ & .724 & $\begin{array}{l}\text { 43. I respect } \\
\text { others }\end{array}$ & .625 & 10. I am shy & .690 & $\begin{array}{l}\text { 1. I am chosen } \\
\text { as leader }\end{array}$ & .613 \\
\hline 21. I support others & .740 & $\begin{array}{l}\text { 35. I avoid } \\
\text { contact }\end{array}$ & .623 & $\begin{array}{l}\text { 18. I accept } \\
\text { majority } \\
\text { decisions }\end{array}$ & .562 & $\begin{array}{l}\text { 16. I am } \\
\text { nervous when } \\
\text { I need to talk }\end{array}$ & .617 & $\begin{array}{l}\text { 19. I am } \\
\text { popular }\end{array}$ & .584 \\
\hline $\begin{array}{l}\text { 45. I am kind to those } \\
\text { who present } \\
\text { problems }\end{array}$ & .676 & $\begin{array}{l}\text { 5. I prefer } \\
\text { isolated } \\
\text { locations }\end{array}$ & .607 & $\begin{array}{l}\text { 46. I correct } \\
\text { other } \\
\text { delicately }\end{array}$ & .556 & $\begin{array}{l}29 . \quad \text { I am } \\
\text { embarassed } \\
\text { when warned }\end{array}$ & .551 & $\begin{array}{l}\text { 41. I am } \\
\text { chosen } \\
\text { judge }\end{array}$ & .573 \\
\hline $\begin{array}{l}\text { 31. I worry that no } \\
\text { one gets set aside }\end{array}$ & .659 & $\begin{array}{l}\text { 47. I feel } \\
\text { without energy }\end{array}$ & .545 & $\begin{array}{l}27 . \text { I talk and } \\
\text { argue calmly }\end{array}$ & .546 & $\begin{array}{l}\text { 3. I am scared } \\
\text { when i don't } \\
\text { know } \\
\text { something }\end{array}$ & .511 & $\begin{array}{l}\text { 30. I like to } \\
\text { coordinate }\end{array}$ & .561 \\
\hline $\begin{array}{l}\text { 2. I am interested in } \\
\text { what happens to } \\
\text { others }\end{array}$ & .631 & $\begin{array}{l}11 . \quad \text { I only } \\
\text { integrate } \\
\text { groups when } \\
\text { forced }\end{array}$ & .430 & 9. I am nice & .492 & $\begin{array}{l}26 . \quad \text { When } \\
\text { facing new } \\
\text { situations } \quad \text { I } \\
\text { feel afraid }\end{array}$ & .502 & $\begin{array}{l}\text { 49. I usually } \\
\text { take initiative }\end{array}$ & .503 \\
\hline $\begin{array}{l}\text { 7. I help those } \\
\text { rejected by the group }\end{array}$ & .609 & $\begin{array}{l}\text { 17. I loose } \\
\text { notion of what } \\
\text { happens }\end{array}$ & .413 & $\begin{array}{l}\text { 15. I wait } \\
\text { calmly for } \\
\text { my turn }\end{array}$ & .466 & 44. I cry easily & .492 & $\begin{array}{l}\text { 34. Others } \\
\text { imitate me. }\end{array}$ & .488 \\
\hline
\end{tabular}




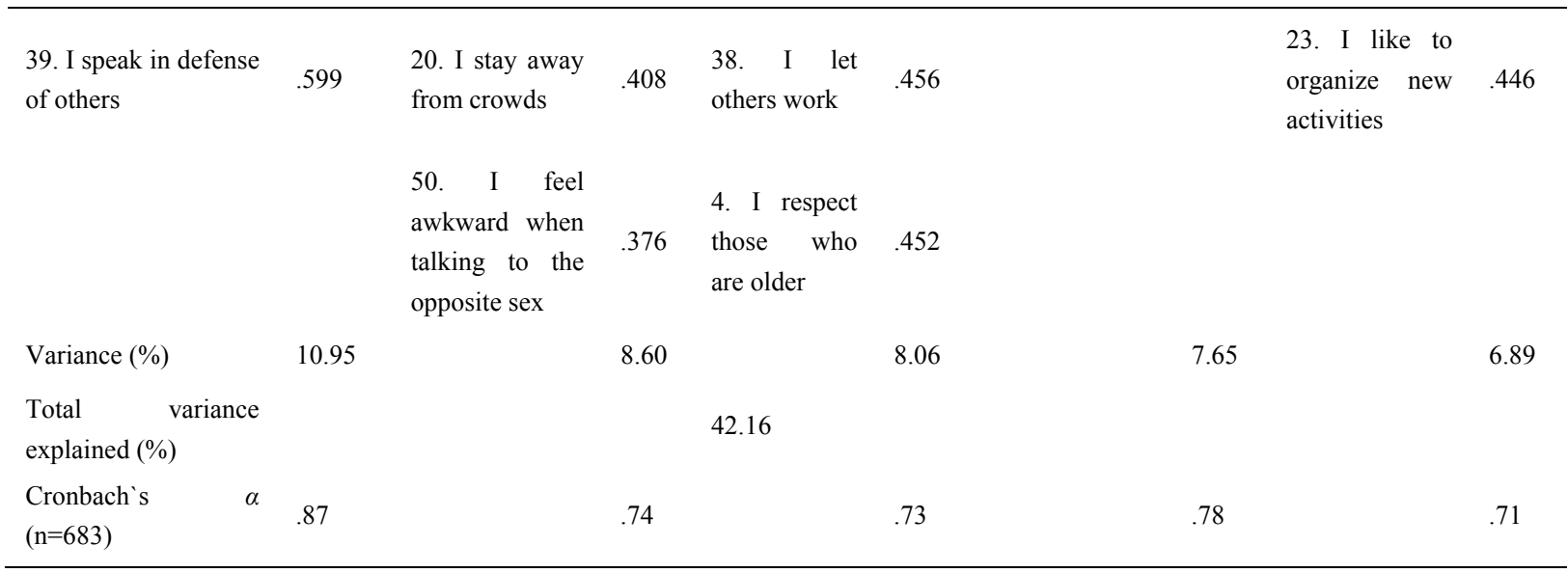

Each factor presents items with adequate loadings, and they account for balanced percentages of variance, as we can observe in table 1 (the items are displayed in a reduced version). Factor 1 is composed by eight items and it corresponds conceptually to Social awareness. Factor 2 represents the dimension of Social isolation, in this factor there was an item (50) that was withdrawn from the final version of the scale because it presented a high loading in another factor (.364 in factor 4), as such the scale is therefore composed by 8 items. Factor 3 corresponds to Self-control, it was also necessary to exclude an item (46) in this dimension since it presented a high secondary loading in factor 1 (.378), therefore 8 items remained. Factor 4, composed by 7 items, is the shortest scale, and can be identified as Social anxiety. Finally, factor 5, composed by 8 items, represents Relationship Skills. So the final version of the questionnaire is composed by 39 items, organized into five scales.

\subsection{Reliability}

The subscales of the QACSE present adequate values of internal consistency, according to the criteria established by Cicchetti (1994), as it can observed in Table 1. In the Social awareness subscale internal consistency can be considered good $(\alpha=.87)$, while in the other subscales the Cronbach's $\alpha$ values can be deemed acceptable, varying between .71 and .78 . Regarding time stability, 308 students filled the questionnaire again, three months after the first application, with significant correlations, all above .60, which, according to Cicchetti (1994), is a good level of stability: Self-control (.66); Social awareness (.63); Relationship Skills (.65); Social isolation (.60); Social anxiety (.68).

\subsection{Validity}

\subsubsection{Concurrent Validity}

Table 2. Correlations between Self-report results between the $Q A C S E$ and the $B A S-3(\mathrm{~N}=114)$

\begin{tabular}{llllll}
\hline QACSE & $\begin{array}{l}B A S-3 \\
\text { Self-control } \\
\text { Social Situations }\end{array}$ & $\begin{array}{l}\text { Consideration } \\
\text { for Others }\end{array}$ & Leadership & $\begin{array}{l}\text { Social } \\
\text { Isolation }\end{array}$ & $\begin{array}{l}\text { Social } \\
\text { Anxiety }\end{array}$ \\
\hline Self-control & $.352^{* *}$ & .114 & .121 & -.007 & .050 \\
Social Awareness & .067 & $.468^{* *}$ & .131 & -.015 & .168 \\
Relationship Skills & .060 & .163 & $.599^{* *}$ & -.046 & -.020 \\
Social Isolation & -.088 & -.103 & -.174 & $.404^{* *}$ & $.370^{* *}$ \\
Social Anxiety & -.089 & -.071 & -.238 & .223 & $.603^{* *}$ \\
\hline
\end{tabular}

Note. ${ }^{*} \mathrm{p}<.01 ;{ }^{* *} \mathrm{p}<.001$ 
As it can observed in Table 2, the results from QACSE are positively and significantly correlated with the results of the BAS-3 in the correspondent scales. It is worth mentioning that the Social isolation subscale of the QACSE presents a positive and significant correlation with both its corresponding subscale in the $B A S-3$, as well as with the Social anxiety subscale of the same instrument.

\subsubsection{Convergent Validity}

Six teachers (three from the 7th grade and three from the 8th grade) filled the teacher version (QACSE-P) regarding 111 students. The self-report were positively and significantly correlated $(p<.01)$ with the teachers reports in three of the five dimensions, namely: Self-control (.26); Relationship Skills (.22) and Social anxiety $(.22)$ and very significantly $(\mathrm{p}<.001)$ in the Social awareness subscale (.36). The exception being the Social isolation subscale where there was no significant correlation between self and teacher reports. Each dimension of the QACSE only presented significant correlations with the corresponding dimension of the QACSE-P.

\subsection{Gender and Developmental Effects}

Table 3. Means and standard deviations in QACSE scales, by gender

\begin{tabular}{lllll}
\hline & \multicolumn{3}{c}{ Gender } \\
\cline { 2 - 5 } & Boys $(\mathrm{n}=367)$ & & Girls $(\mathrm{n}=316)$ & \\
& $M$ & $S D$ & $M$ & 4.23 \\
\hline Self-control & 16.12 & 4.22 & 17.49 & 4.43 \\
Social Awareness & 12.33 & 4.21 & 15.12 & 3.47 \\
Relationship Skills & 9.88 & 3.51 & 8.95 & 3.42 \\
Social Isolation & 5.81 & 3.63 & 5.36 & 4.20 \\
Social Anxiety & 7.29 & 3.86 & 8.92 & \\
\hline
\end{tabular}

Regarding gender, there are very significant differences $(\mathrm{p}<.001)$ in four dimensions: Self-control, $t(680)=-4.23$; Social awareness, $t(680)=-8.21$; Relationship Skills, $t(677)=3.44$ and Social anxiety, $t(680)=-5.27$. Therefore, as we can observe in table 3, girls presented higher levels of Self-control and Social awareness, as well as higher levels of Social anxiety than boys. However, boys reported higher levels of Relationship Skills.

There were no significant difference between students according to their grade; however there were several significant differences according to students' age. In order to perform this analysis we removed from the sample the students who were $16(n=23)$ and $17(n=5)$ years old due to the reduced size of these groups. There were significant differences in the dimensions of Self-control, $F(4,648)=7.69 ; \mathrm{p}<.001$ and Social isolation, $F(4,648)=3.34 ; \mathrm{p}=.01$. Regarding Self-control, the post-hoc analysis revealed that it diminishes with age, with 11 and 12 year old students presenting significantly higher levels than 14 and 15 year old students, and 13 year old students presenting significantly higher levels than 15 year old students.

\section{Discussion}

The present study demonstrated the existence of good psychometric characteristics of the Social and Emotional Competences Evaluation Questionnaire ( $Q A C S E$ ) in a sample of high middle school students (7th to 9th grade). The factorial analysis supports the existence a multidimensional structure composed by five factors, which is similar to the teacher's version. As such, these results are in line with the theoretical framework, which proposes that there are several differentiable social and emotional competences, which are simultaneously connected between them.

The $Q A C S E$ is therefore composed by five scales: Self-control, which evaluates behavioural reactions in conflict situations, respect towards others, the fulfilment of social rules and responsibility; Social Awareness, that assesses the degree of consideration or preoccupation with others, particularly those who are going through problems or are rejected by the group; Relationship Skills, refers to the popularity among others as well as cooperation and degree of initiative in group tasks; Social Isolation, which evaluated isolation, aloofness and 
distance from the group; Social Anxiety, measuring anxiety, nervousness and fear, as well as shame when performing social tasks. The five factors present in the factorial analysis present a strong relation with the theoretical background adopted (CASEL, 2005), specifically with Self-Control, Social Awareness and Relationship Skills, as well as element of Self-Awareness (such as Social Anxiety) and Relationship Skills (Social Isolation). The scales are composed by a reduced number of items, which is an essential element for its efficient application, as well as for its acceptance by students and schools.

The questionnaire presented very satisfying level of internal consistence and test-retest stability, attesting for its reliability. Cronbach's alpha values indicated that all five scales had an adequate internal consistence, with the Social Awareness scale even presenting a good level of internal consistence. Good test-retest reliability was also found for all the scales in the questionnaire, according to the criteria established by Cicchetti (1994). Therefore, the evaluation of social and emotional competences will present a high degree of stability if there are no interventions carried out. It is important to notice that the time difference adopted for the analysis time-retest reliability was three months, in line with what was practice among other similar instruments (e.g. original $B A S-3$; Silva \& Martorell, 1995), but the length of this interval is not normally reported in Portuguese adaptations (e.g. BAS-3; Ferreira \& Rocha, 2004; SSRS; Lemos \& Menezes, 2002; SSBS-2; Raimundo et al., 2012).

The questionnaire psychometric characteristics give assurances regarding the quality of information gathered both in terms of reliability and of validity (construct validity, through factorial validity). The data gathered also supports criterion validity, both concurrent and convergent validity, which means that the present instrument represents an evolution from previous instruments regarding convergent validity, since, in previous instruments, most dimensions did not present significant correlations between self-report and teacher reports. This was the case of the $B A S-3$, in which three (out of five) subscales (Social awareness, Social isolation, Leadership) were not correlated with their counterparts in the BAS-1 (Silva \& Martorell, 2001). In the present instrument this is only the case of Social isolation, this problem probably stems from the difficulty that teachers face when they have to evaluate the levels of students' Social isolation outside the classroom. Through the analysis of concurrent validity we can confirm that the QACSE is effectively assessing the competencies it is supposed to assess. However, there seems to be a connection between the dimensions of Social isolation and Social anxiety, probably because they coexist in real life settings.

Among the results from differential statistics the gender differences stand out with girls reporting higher levels of Self-control, Social awareness and Social anxiety. These results are common in other self-report instruments such as the $B A S-3$ which presents the same pattern in the Portuguese adaptation (Ferreira \& Rocha, 2004). Also, in the teacher report instruments, such as the SSBS-2 (Raimundo et al., 2012), there is an advantage of girls in Self-control. Some parent reports present similar results, Silva and Martorell (2001) in the Bateria de Socialización-2, reported that girls had higher levels of Social Sensibility and Self-control than the boys.

The differences encountered regarding age in the dimension of Self-control, with younger students reporting higher levels, are quite common in both other self-report instruments (e.g. BAS-3; Ferreira \& Rocha, 2004), and teacher reports (e.g. SSBS-2; Raimundo et al., 2012) as well. It is worth mentioning that unlike the BAS-3, in the QACSE there is no increase of Social anxiety, or decrease in the levels of Relationship skills. Generally the differential results are in line with the literature about this kind of instruments.

Notwithstanding, there are limitations to the present work that are due to the sample characteristics. The sample has a reduced number of 9th grade students and this situation introduces some limitations to the conclusions that can be made. This problem does not extend to age, as there is a balanced participation of students from 12 to 14 years.

Another limitation of the QACSE stems from the need to increase the correspondence between the dimensions of the instrument and the theoretical framework proposed by CASEL (2005), for which the addition of a Responsible decision making subscale would be important. This dimension was not a part of any of the original instruments from which the present questionnaire was based upon, but it would be crucial to integrate this dimension in order to improve its usefulness as a tool to analyse the efficacy of SEL programs. Another direction worth following would be the conducting studies that deepen the convergent validity of the questionnaire, by analysing the association of its subscales with other indicators of social and emotional adjustment, such as social, emotional and academic Self-concept (Coelho \& Figueira, 2011), important components of the dimension of Self-awareness. 


\section{Conclusion}

In conclusion, results showed the $Q A C S E$ to be a valid and reliable instrument, allowing a fast application (it takes about 10 minutes to be filled out) and appropriate for individual or group use in order to carry out detailed assessment of social and emotional competencies and SEL promotion programs.

\section{Acknowledgements}

This project was supported by the municipality of Torres Vedras.

\section{References}

Cicchetti, D. V. (1994). Guidelines, criteria, and rules of thumb for evaluating normed and standardized assessment instruments in psychology. Psychological Assessment, 6(4), 284-290. http://dx.doi.org/10.1037/ 1040-3590.6.4.284

Coelho, V., \& Figueira, A. (2011). Project "Positive Attitude": Promoting school success through social and emotional abilities development. Design for elementary and middle school students in Portugal. Interamerican Journal of Psychology, 45(2), 185-192.

Coelho, V., Sousa, V., \& Figueira, A. P. (2014). The impact of a school-based social and emotional learning program on the self-concept of middle school students. Psicodidactica, 19(2), 347-365. http://dx.doi.org/ 10.1387/RevPsicodidact.10714

Collaborative for Academic, Social, and Emotional Learning. (2005). Safe and sound: An educational leader's guide to evidence-based social and emotional learning programs-Illinois edition. Chicago: CASEL.

Collaborative for Academic, Social, and Emotional Learning. (2012). 2013 CASEL guide: Effective social and emotional learning programs (Preschool and elementary school edition). Chicago, IL.

Durlak, J., Weissberg, R., Dymnicki, A., Taylor, R., \& Schellinger, K. (2011). The impact of enhancing students' social and emotional learning: A meta-analysis of school-based universal interventions. Child Development, 82, 405-432. http://dx.doi.org/10.1111/j.1467-8624.2010.01564.x

Ferreira, C., \& Rocha, A. M. (2004). BAS-3, Bateria de Socialização (Auto-avaliação) [BAS-3, Social Skills Battery (Self-Report)]. Lisboa: CEGOC.

Floyd, F. J., \& Widaman, K. F. (1995). Factor analysis in the development and refinement of clinical assessment instruments. Psychological Assessment, 7(3), 286-299. http://dx.doi.org/10.1037/1040-3590.7.3.286

Greenberg, M. et al. (2003). Enhancing school-based prevention and youth development through coordinated social, emotional, and academic learning. American Psychologist, 58, 466-474. http://dx.doi.org/10.1037/0003-066X.58.6-7.466

Gresham, F. M., \& Elliott, S. N. (1990). Social skills rating system: Manual. Circle Pines, MN: American Guidance Service.

Lemos, M. S., \& Meneses, H. I. (2002). A avaliação da competência social: Versão portuguesa da forma para professores do SSRS. Psicologia: Teoria and Pesquisa, 18(3), 267-274. http://dx.doi.org/10.1590/ S0102-37722002000300005

Merrell, K. W. (2002). School Social Behavior Rating Scales (2nd ed.). Eugene, OR: Assessement-Intervention Resources.

Merrell, L. (2001). Assessment of children's social skills: Recent developments, best practices, and new directions. Exceptionality, 9, 3-18. http://dx.doi.org/10.1080/09362835.2001.9666988

Raimundo, R., Carapito, E., Pereira, A. I., Marques-Pinto, A., Lima, L., \& Ribeiro, T. (2012). School social behavior scales (SSBS2): An adaptation study of the portuguese version of the social competence scale. Spanish Journal of Psychology, 15, 1473-1484. http://dx.doi.org/10.5209/rev_SJOP.2012.v15.n3.39431

Sandell, R., Kimber, B., Andersson, M., Elg, M., Fhärm, L., Gustafsson, N., \& Söderbaum, W. (2012). Psychometric analysis of a measure of socio-emotional development in adolescents. Educational Psychology in Practice, 28, 395-420. http://dx.doi.org/10.1080/02667363.2012.726196

Silva, F., \& Martorell, M. C. (2001). BAS 1-2: Bateria de Socialización (Para professores y Padres): Manual (4a edición) [BAS 1-2, Social Skills Battery (Teacher and Parents Form): Manual (4th ed.)]. Madrid, Spain: TEA Ediciones. 
Silva, F., \& Martorell, M. C. (1995). BAS3: Bateria de Socialización (Autoevaluación) [BAS-3, Social Skills Battery (Self-Report)]. Madrid, Spain: TEA Ediciones.

Sklad, M., Diekstra, R., DeRitter, M., Ben, J., \& Gravesteijn, C. (2012). Effectiveness of school-based universal social, emotional, and behavioral programs: Do they enhance students' development in the area of skill, behavior and adjustment? Psychology in the Schools, 49, 892-909. http://dx.doi.org/10.1002/pits.21641

Zins, W. W., \& Walberg. (2004). Building Academic Success on Social and Emotional Learning (SEL): What Does the Research Say? New York: Teachers College Press.

\section{Copyrights}

Copyright for this article is retained by the author(s), with first publication rights granted to the journal.

This is an open-access article distributed under the terms and conditions of the Creative Commons Attribution license (http://creativecommons.org/licenses/by/3.0/). 